\title{
Associations between Personal Exposure to Metals in Fine Particulate Matter and Autonomic Nervous System Dysfunction among Healthy Adults
}

\author{
Yi-Hsueh Liao ${ }^{1,2,4,5,6}$, Wei-Liang Chen ${ }^{3,6}$, Chung-Ching Wang ${ }^{3,6}$, Ching-Huang Lai ${ }^{4 *}$ \\ ${ }^{1}$ Department of Family Medicine, Shuang Ho Hospital, Taipei Medical University, New Taipei City 23561, Taiwan \\ ${ }^{2}$ Division of Geriatric Medicine, Department of Family and Community Medicine, Tri-Service General Hospital, Taipei \\ 11490, Taiwan \\ ${ }^{3}$ Division of Family Medicine, Department of Family and Community Medicine, Tri-Service General Hospital, Taipei \\ 11490, Taiwan \\ ${ }^{4}$ School of Public Health, National Defense Medical Center, Taipei 11490, Taiwan \\ ${ }^{5}$ School of Medicine, Taipei Medical University, Taipei 11031, Taiwan \\ ${ }^{6}$ School of Medicine, National Defense Medical Center, Taipei 11490, Taiwan
}

\begin{abstract}
The impact of airborne particulate matter and its metal components on autonomic nervous system (ANS) dysfunction in healthy subjects remains unclear. The aim of this study was to examine the effects of personal exposure to airborne particulate matter on the ANS in young, healthy adults. This longitudinal study recruited 82 adults aged 20 to 35 years from districts A and B. District A had lower ambient $\mathrm{PM}_{2.5}$ levels than district B. Personal exposure to fine particulate matter and metals in $\mathrm{PM}_{2.5}$ was collected every two months. The heart rate variability (HRV) indices of each participant were measured three times. The relationship among the $\mathrm{PM}_{2.5}$ concentration, metals in $\mathrm{PM}_{2.5}$ and $\mathrm{HRV}$ level was investigated by a generalized estimating equation with an autoregression of order 1. The average age of the participants was $26.4 \pm 3.6$ years in district $\mathrm{A}$ and $21.9 \pm 1.5$ years in district $\mathrm{B}(p<0.001)$. After adjusting for covariables, significant changes in $\log _{10}$ standard deviation of normal to normal (SDNN) intervals and $\log _{10}$ square root of the mean of the sum of the squares of differences (r-MSSDs) were related to unit changes in $\log _{10}$ iron in $\mathrm{PM}_{2.5}(\beta=-0.033,95 \% \mathrm{CI}=-0.060$ to $-0.0056, p<$ 0.05 and $\beta=-0.041,95 \% \mathrm{CI}=-0.075$ to $-0.0076, p<0.05$, respectively). The $\log _{10}$ SDNN levels were significantly positively related to $\log _{10}$ gallium in $\mathrm{PM}_{2.5}(\beta=0.054,95 \% \mathrm{CI}=0.0064$ to $0.10, p<0.05)$. Exposure to heavy metals in airborne particulate matter was associated with ANS dysfunction.
\end{abstract}

Keywords: Particulate matter; Metals; Autonomic nervous system.

\section{INTRODUCTION}

Human beings need sunlight, air, and water. Currently, air pollution, such as fine particulate matter, has become a major problem in daily life in many countries. In large cities, the major source of airborne particulate matter is emitted during the combustion of fuels. Industry emissions and vehicle emissions are common sources of fine particulate matter $\left(\mathrm{PM}_{2.5}\right)$. In addition, this kind of airborne particulate matter can absorb metals and polycyclic aromatic hydrocarbons (PAHs) (Schwela, 2000). In Taiwan, the metallic elements $\mathrm{Fe}, \mathrm{Cd}, \mathrm{Pb}, \mathrm{Zn}, \mathrm{Cr}, \mathrm{Mn}$ and $\mathrm{Ni}$ were the largest components in airborne particulate matter and were produced by traffic

\footnotetext{
* Corresponding author.

Tel.: +886-2-8792-3100 ext. 18464

E-mail address:1gh@mail.ndmctsgh.edu.tw
}

and industry emissions (Fang et al., 2003).

In previous studies, exposure to airborne particulate matter was associated with death or cardiovascular risks (Riediker et al., 2004; Madsen et al., 2012; Krishnan et al., 2013; Fiordelisi et al., 2017; Fang et al., 2019). Increasing evidence implicates airborne particulate matter as a potential cause of central nervous system (CNS) dysfunction (Wang et al., 2017; Kim et al., 2018). One hypothesis for how airborne particulate matter affects the CNS is that particulate matter travels through the olfactory bulb and blood-brain barrier to the brain, with toxic effects on the CNS. In addition, particulate matter may directly or indirectly damage physiological barriers, such as the blood-brain barrier (Block and CalderonGarciduenas, 2009). The other hypothesis is that particulate matter causes autonomic nervous system (ANS) dysfunction through an effect on the pulmonary neural reflex. In this way, particulate matter would affect one's heart rhythm (Brook et al., 2010).

ANS activity can be evaluated by heart rate variability 
(HRV). Measurement of HRV is a non-invasive method to assess ANS imbalances (Moritani et al., 2005). Recent studies have suggested that air pollution is associated with an HRV reduction in elderly adults, healthy adults and infants (Adar et al., 2007; Wu et al., 2010; Mirowsky et al., 2015; Cowell et al., 2019). A decrease in HRV is related to ANS dysfunction. Moreover, metal particulate exposure affects the ANS (Chen et al., 2006). Nickel, manganese, and calcium in airborne PM were related to a decrease in HRV (Wu et al., 2012; Chuang et al., 2013). Even transient exposure to PM may cause ANS imbalances in young adults (Jia et al., 2018). Furthermore, although an effect of metal particulates on HRV has been reported (Shutt et al., 2017), no published studies have characterized the impact of airborne particulate matter and its metal components on adverse effects such as ANS dysfunction in healthy adults. Thus, we conducted a longitudinal research study to examine the associations between personal exposure to metals in fine particulate matter and ANS dysfunction in healthy adults.

\section{METHODS}

\section{Participants}

This was a longitudinal-design study conducted in northern Taiwan from February and June 2014. Initially, 82 young adults aged 20 and older were eligible. Participants were from districts A and B of northern Taiwan. District A (lowlevel exposure) had lower ambient $\mathrm{PM}_{2.5}$ levels than district B (high-level exposure) according to the data obtained from the monitoring sites of the environmental protection administration (EPA). Healthy non-smokers were recruited. During February and June 2014, personal $\mathrm{PM}_{2.5}$ exposure and in- $\mathrm{PM}_{2.5}$ metal data were collected every two months. HRV was also measured three times every two months. We collected individuals' air samples within the personal breathing zone for 24 hours (from 8:00 AM on day 1 to 8:00 AM on day 2). A self-administered questionnaire was also completed by the study subjects. An HRV assessment was recorded on the following morning (day 2). The questionnaire collected information regarding the sampling area, participants' characteristics, cigarettes smoked, and indoor time. HRV data were collected the same day. A flow chart of the study design is shown in Fig. 1. Some participants were lost to follow-up during the study period; thus, we recruited new study participants in April and June. In total, 57 study subjects completed all 3 measurements, 17 study subjects completed 2 measurements, and 5 study subjects completed one measurement. The study was approved by the Institutional Review Board of Tri-Service General Hospital in accordance with the revised Declaration of Helsinki. All participants provided written informed consent.

\section{PM2.5 Personal Exposure Assessment}

To assess $\mathrm{PM}_{2.5}$ personal exposure, personal air sampling was performed by a $2.5-\mu \mathrm{m}$ impactor (PEM; SKC Inc., PA, USA) and a pump (Gilian Gilair, Sensidyne Inc., FL, USA). We used a quartz fibre filter (2500 QAT-UP, Purtram, Conn., USA) to collect personal air samples. After the air was passed through a static neutralizer, the filters were weighed. We used a microbalance (Mettler-Toledo, MT5, Greifensee, Switzerland) with $1-\mu \mathrm{g}$ reading to analyse the weight. The laboratory had a relative humidity of $60 \%$ and a constant temperature. The detection limit for mass concentration was $2.11 \mathrm{\mu g} \mathrm{m}^{-3}$.

\section{Metal Composition and Concentration Measurements in PM2.5}

Participants were recruited from 2 districts of an urban area of northern Taiwan. In the urban area of Taiwan, the major source of metals in $\mathrm{PM}_{2.5}$ came from vehicle emissions. Three of the most common metals in $\mathrm{PM}_{2.5}$ were iron $(\mathrm{Fe})$, nickel (Ni), and manganese (Mn) (Fang et al., 2003). Furthermore, between the 2 districts, district B was located close to industrial areas and residential areas. Because electronics technologies have expanded in industry, we were interested in the potential personal exposure to titanium (Ti) and gallium (Ga). Fe, Ti, Ni, Mn, and Ga composition and concentration measurements. To assess the participants' exposure to heavy metals in $\mathrm{PM}_{2.5}$, we collected personal breathing-zone air samples from every study participant for 24 hours. After sampling, a pressure bomb digestion system consisting of a $25 \mathrm{~mL}$ polytetrafluoroethylene (PTFE) vessel and a thermostatically controlled heating block (supplied by Berghof, Engen, Germany) was used for sample digestion

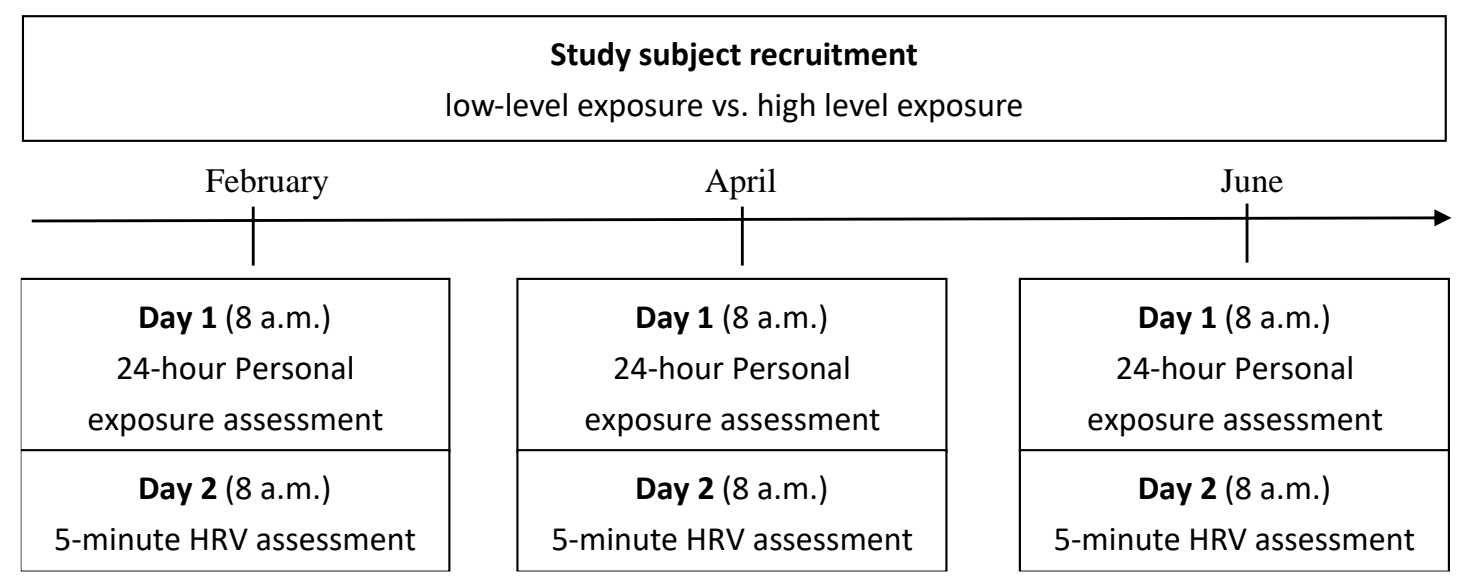

Fig. 1. Flowchart of the exposure assessment. 
(Wang et al., 1997). The Teflon filters were placed in $25 \mathrm{~mL}$ PTFE containers and a mixture of $3 \mathrm{~mL}$ nitric acid $\left(\mathrm{HNO}_{3}\right)$, $5 \mathrm{~mL}$ perchloric acid $\left(\mathrm{HClO}_{4}\right)$, and $2 \mathrm{~mL}$ hydrofluoric acid (HF) was added. The container was sealed, transferred into a high-pressure bomb, and heated at $170^{\circ} \mathrm{C}$ for $5 \mathrm{hr}$ to facilitate complete dissolution. After digestion, the sample solution was transferred into a PTFE beaker and heated gently at roughly $80^{\circ} \mathrm{C}$ to allow the $\mathrm{HF}$ to evaporate. The residue was then diluted to $10 \mathrm{~mL}$ with $2 \% \mathrm{HNO}_{3}$ and measured with an ICP-MS instrument (ICP-MS, Agilent 7500cx, Agilent Technologies Inc., USA). In addition to sample analysis, a recovery test of the National Institute of Standards and Technology (NIST) standard reference materials (SRM) 1648 on blank filters was also performed. Details of operating conditions for the ICP-MS instruments were presented in a previous paper (Wang et al., 1997).

Quality assurance/quality control (QA/QC) procedures associated with these methods involved calibration, a recovery test using standard reference materials, and protocols for calculating the method detection limits (MDL). The average recoveries of metals ranged from 83 to $108 \%$. The relative standard deviation (RSD) of the data was less than $10 \%$, representing a high degree of reproducibility. The detection limits for $\mathrm{Cd}, \mathrm{Ni}, \mathrm{As}, \mathrm{Pb}, \mathrm{Cu}$, and $\mathrm{Zn}$ were $0.02,0.20,0.05$, $2.94,5.43$, and $18.40 \mathrm{ng} \mathrm{g}^{-1}$, respectively.

\section{Ambient PM2.5, Noise and Meteorological Data}

We obtained ambient $\mathrm{PM}_{2.5}$ levels every hour and temperature, noise and relative humidity data every day from one monitoring site each in districts $\mathrm{A}$ and $\mathrm{B}$. These data were collected from the EPA monitoring sites.

\section{HRV}

To measure each HRV index, we used an HRV analyser (SA-3000P, MEDICORE CO., Korea). HRV indices included the standard deviation of normal to normal (SDNN) intervals and the square root of the mean of the sum of the squares of differences (r-MSSD) between adjacent NN intervals. Trained interviewers performed the HRV index measurements. Each time, we measured a complete fiveminute segment of the NN interval, including the SDNN and r-MSSD. Namely, we calculated these HRV index on 5-min segment of NN interval we obtained.

\section{Statistical Analyses}

Statistical analyses were performed with Stata 12 software (College Station, TX, USA). Continuous data were described using means \pm standard deviations, and numerical data were described using numbers and percentages. We described the distributions of $\mathrm{PM}_{2.5}$ exposure and metals in $\mathrm{PM}_{2.5}$ in geometric means $(95 \% \mathrm{CI})$. To examine the trend of each measurement, trend tests were performed. To examine the distribution of the data, we used the Shapiro-Wilk normality test. The concentration of $\mathrm{PM}_{2.5}$, metals in $\mathrm{PM}_{2.5}$ and levels of HRV were not normally distributed (all $\mathrm{p}<0.01$ ). Thus, the independent and dependent variables were logarithmically (log) transformed. We obtained previous 24-hour mean measurements of the ambient $\mathrm{PM}_{2.5}$ levels, temperature, noise, and relative humidity data to match the corresponding the HRV assessment of the study subjects according to districts A or B. Our study was a longitudinal research study, and the $\mathrm{PM}_{2.5}$ concentrations and HRV levels were repeatedly measured three times every two months. A generalized estimating equation (GEE) with an autoregression of order 1 (AR[1]) was set to assess the effects of the concentration of $\mathrm{PM}_{2.5}$ and metals in $\mathrm{PM}_{2.5}$ on the levels of HRV (Zeger and Liang, 1986). We used GEE analysis to estimate Standard Errors (SEs) while taking into consideration of repeated measurements of same subject effect. The independent variables were the concentration of $\mathrm{PM}_{2.5}$ and metals in $\mathrm{PM}_{2.5}$, and the dependent variables were the levels of HRV. We used $\mathrm{PM}_{2.5}$ and HRV data as continuous variable. We did not set a cut-off point for HRV levels to distinguish healthy or unhealthy. We adjusted the confounding variables of age, gender, sampling area, sampling time, day of the week, temperature, humidity, and noise. Temperature and humidity were common confounders of $\mathrm{PM}_{2.5}$, and noise was a common confounder of HRV. A $p$ value of $<0.05$ was considered statistically significant.

\section{RESULTS}

\section{Characteristics of the Study Subjects}

Table 1 shows a total of 82 adults were included in the analysis, of whom 33 were male (40\%) and 61\% were from district A. The average age of the participants was $26.4 \pm$ 3.6 years in district A and $21.9 \pm 1.5$ years in district B $(p<$ $0.001)$. The mean body mass index (BMI) of the participants

Table 1. Characteristics of the participants at baseline $(n=82)$.

\begin{tabular}{lllll}
\hline & District A (n=50) & District B $(\mathrm{n}=32)$ & Total $(\mathrm{n}=82)$ & $p$-value \\
\cline { 2 - 5 } & Mean \pm SD / n (\%) & Mean \pm SD /n $(\%)$ & Mean \pm SD /n $(\%)$ & $<0.001^{* * *}$ \\
\hline Age (years) & $26.4 \pm 3.6$ & $21.9 \pm 1.5$ & $24.6 \pm 3.7$ & 0.94 \\
BMI & $22.9 \pm 3.4$ & $22.9 \pm 3.3$ & $22.9 \pm 3.3$ & $<0.001^{* * *}$ \\
Indoors time (hours) & $22.9 \pm 1.1$ & $20.7 \pm 1.9$ & $22.0 \pm 1.8$ & $0.024^{*}$ \\
Gender & & & & \\
$\quad$ Female & $25(50)$ & $24(75)$ & $49(60)$ & 0.069 \\
$\quad$ Male & $25(50)$ & $8(25)$ & $33(40)$ & \\
Smoking & & & $73(89)$ & \\
$\quad$ No & $42(84)$ & $31(97)$ & $9(11)$ & \\
$\quad$ Yes & $8(16)$ & $1(3)$ &
\end{tabular}

${ }^{\dagger}$ Independent t-test, Chi-square test ${ }^{* * *} p<0.001{ }^{* *} p<0.01{ }^{*} p<0.05$. 
was $22.9 \pm 3.3 \mathrm{~kg} \mathrm{~m}^{-2}$. Among the participants, $89 \%$ did not smoke. Participants in district A spent more time indoors than those in district B $(p<0.001)$.

\section{Comparison of Personal PM2.5 Exposure in All Participants and Metals in PM 2.5 with Regard to Measurement times}

The levels of $\mathrm{PM}_{2.5}$ and metals in $\mathrm{PM}_{2.5}$ exposure at each measurement are shown in Table 2. Personal $\mathrm{PM}_{2.5}$ levels were highest in the first measurement (trend test, $p<0.001$ ). Compared to district $\mathrm{A}$, district $\mathrm{B}$ had higher personal $\mathrm{PM}_{2.5}$ levels. In the first measurement, district $B$ had the highest levels of nickel and manganese in $\mathrm{PM}_{2.5}$ (trend test, $p<$ 0.008 and $p<0.001$, respectively). In the third measurement, district $\mathrm{A}$ had the highest level of iron in $\mathrm{PM}_{2.5}$ (trend test, $p$ $<0.001)$. In the first measurement, district $A$ had the highest level of gallium in $\mathrm{PM}_{2.5}$ (trend test, $p<0.001$ ).

\section{Comparison of HRV in All Participants with Regard to Measurement Times}

The HRV indices of the participants are shown in Table 3. In the third measurement, the $\log _{10}$ SDNN and $\log _{10}$ r-MSSD levels were higher in district $B$ than in district A. In the first measurement, district $A$ had the highest level of $\log _{10}$ SDNN (trend test, $p<0.007$ ).

\section{Relationships among Personal PM ${ }_{2.5}$ Exposure, Metals in PM2.5 and HRV}

There were no significant associations between Personal $\mathrm{PM}_{2.5}$ exposure levels and $\log _{10}$ SDNN and $\log _{10}$ r-MSSD levels (Table 4). However, after adjusting for confounding variables, significant changes in the $\log _{10}$ SDNN and $\log _{10}$ r-MSSD were related to unit changes in $\log _{10}$ iron in $\mathrm{PM}_{2.5}$ $(\beta=-0.033,95 \% \mathrm{CI}=-0.060$ to $-0.0056, p<0.05)$ and $(\beta$ $=-0.041,95 \% \mathrm{CI}=-0.075$ to $-0.0076, p<0.05)$, respectively. Furthermore, the $\log _{10}$ SDNN levels were significantly positively related to $\log _{10}$ gallium in $\mathrm{PM}_{2.5}(\beta=0.054,95 \%$ $\mathrm{CI}=0.0064$ to $0.10, p<0.05)$. Namely, for every $1 \%$ increase in the $\log _{10}$ iron in $\mathrm{PM}_{2.5}$, our $\log _{10}$ SDNN and $\log _{10}$ r-MSSD decreases by about $0.03 \%$ and $0.04 \%$, respectively. For every $1 \%$ increase in the $\log _{10}$ gallium in $\mathrm{PM}_{2.5}$, our $\log _{10}$ SDNN increases by about $0.05 \%$.

\section{DISCUSSION}

We conducted a longitudinal study that investigated the effects of heavy metals in the airborne particulate matter on the ANS of young adults. Participants in district A were older and spent more time indoors than those in district B. The $\log _{10}$ SDNN level continually decreased in district A during the three measurements. After we adjusted for determinants of airborne particulate matter exposure such as age, gender, sampling area, sampling times, temperature, and relative humidity, significant relationships between iron and gallium in $\mathrm{PM}_{2.5}$ and $\mathrm{HRV}$ were observed.

\section{Result Validity}

This is the first publication to establish the relationship between metal particulates and decreased HRV among young, healthy subjects. There are several strengths in this study. This was a longitudinal-design study; thus, we were able to observe changes over time. Assessments of personal $\mathrm{PM}_{2.5}$ exposure and metals in $\mathrm{PM}_{2.5}$ were conducted. Since comorbidity and smoking may influence the HRV of the study subjects, we recruited healthy, non-smoking college students from two districts of northern Taiwan. We adjusted for sampling temperature and humidity, which are common covariables of particulate matter, and adjusted for sampling noise, which is common covariable of HRV.

\section{Synthesis of Previous Knowledge}

$\mathrm{PM}_{2.5}$ was highest in the first measurement (winter) in the present study. Because of northeastern monsoons in winter, Chinese haze may drive $\mathrm{PM}_{2.5}$ towards northern Taiwan. Chinese haze consists of air pollutants (Zhang and Samet, 2015; Li et al., 2016). District B had higher $\mathrm{PM}_{2.5}$ levels than district $A$ in all 3 measurements. In the first and second measurements, district $\mathrm{B}$ had significantly higher $\mathrm{PM}_{2.5}$ levels than district $\mathrm{A}$ ( $p<0.001$ and $p<0.001$, respectively). In the third measurement, district $\mathrm{B}$ also had higher $\mathrm{PM}_{2.5}$ levels than district $\mathrm{A}$, although the difference was not statistically significant $(p=0.21)$. District B comprises industrial areas and residential areas. By contrast, district A comprises commercial areas and residential areas. Thus, district $\mathrm{B}$ had higher $\mathrm{PM}_{2.5}$ levels than district $\mathrm{A}$. We also collected ambient $\mathrm{PM}_{2.5}$ concentrations from the EPA monitoring site of district $\mathrm{A}$ and $\mathrm{B}$. The ambient $\mathrm{PM}_{2.5}$ levels and personal $\mathrm{PM}_{2.5}$ exposure levels were moderately correlated (Spearman's rho $=0.58, p<0.001$ ). Furthermore, significant associations were not observed between the ambient $\mathrm{PM}_{2.5}$ levels and study subjects' SDNN and r-MSSD levels ( $p=0.19$ and $p=0.43$, respectively).

Most metals in $\mathrm{PM}_{2.5}$, such as titanium, nickel, and gallium, were higher in winter than in spring and summer. These may be due to Chinese haze, wind direction and topography. In our study, iron levels in $\mathrm{PM}_{2.5}$ were higher in summer than in spring and winter, unlike other metals in $\mathrm{PM}_{2.5}$. Among the metals in $\mathrm{PM}_{2.5}$, iron had the highest levels during the three sampling periods. Fang et al. (2003) found that the metallic element iron was one of the most abundant atmospheric aerosol particles in Taiwan. Since iron is also one of the most abundant metals in crustal particles, it likely came from dust and unpaved roads. Thus, iron in $\mathrm{PM}_{2.5}$ was seldom affected by monsoons and did not show increased levels in winter (Li et al., 2016; Chang et al., 2018). Heavy metals in ambient particulate matter come from different sources. For example, aluminium, iron, sodium, magnesium, potassium, calcium and gallium are crustal elements. On the other hand, nickel, zinc and lead are anthropogenic elements (Geiger and Cooper, 2010). In Taiwan, Chen and Lin (2015) also found that iron in $\mathbf{P M}_{2.5}$ mainly came from soil dust and crust.

In the first measurement, the SDNN of the total study subjects' (district A and B) median was $52.58 \mathrm{msec}$ (25-75 percentile $=40.40-63.73(\mathrm{msec})$ ) and the r-MSSD of the total study subjects' median was $35.75 \mathrm{msec}$ (25-75 percentile $=22.80-47.50$ (msec)). In the second measurement, the SDNN of the total study subjects' median was $51.89 \mathrm{msec}$ 


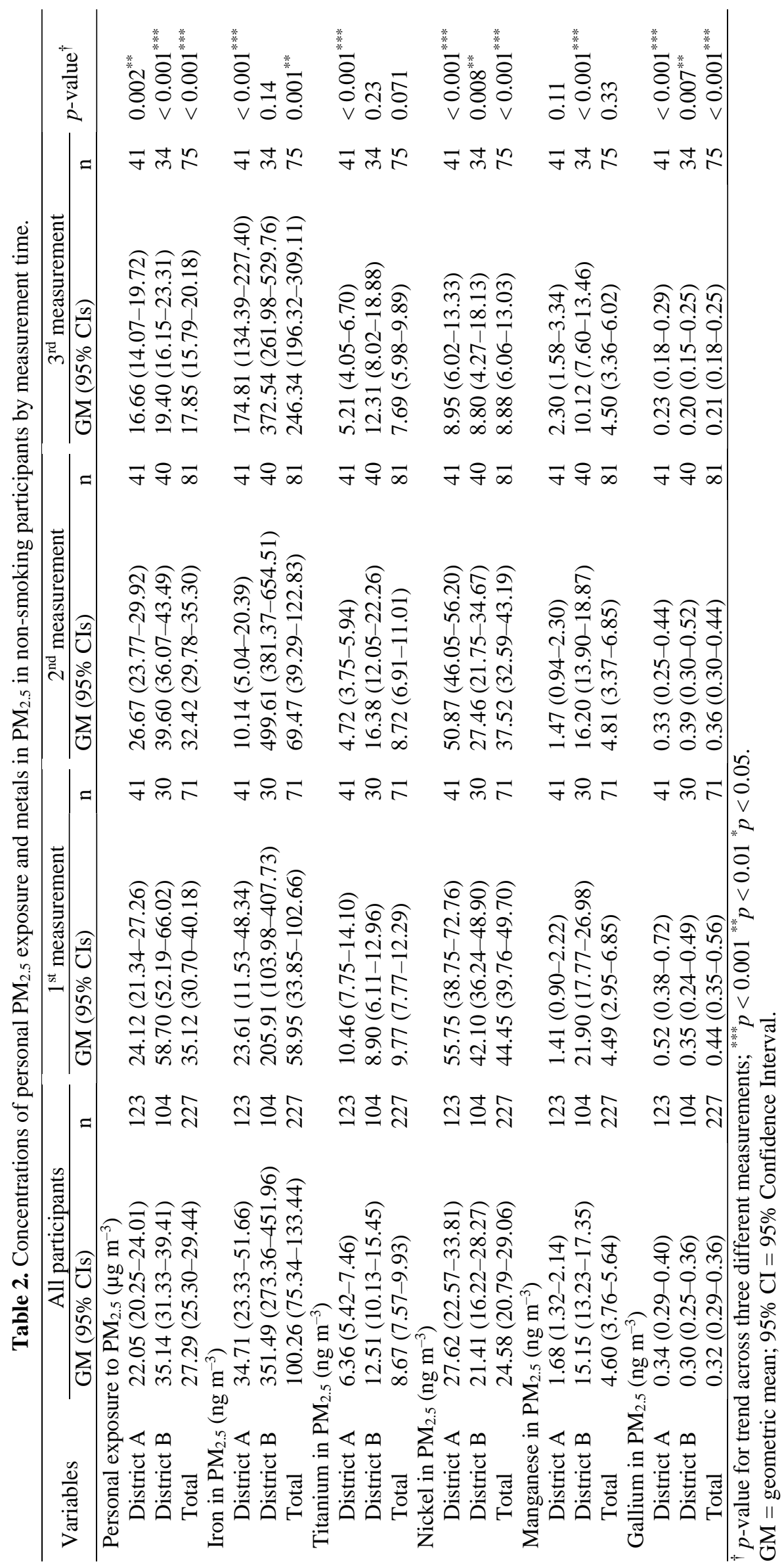


Table 3. HRV in non-smoking participants by measurement time.

\begin{tabular}{|c|c|c|c|c|c|c|c|c|c|}
\hline \multirow{2}{*}{ Variables } & \multicolumn{2}{|c|}{ All participants } & \multicolumn{2}{|c|}{$1^{\text {st }}$ measurement } & \multicolumn{2}{|c|}{$2^{\text {nd }}$ measurement } & \multicolumn{2}{|c|}{$3^{\text {rd }}$ measurement } & \multirow{2}{*}{$p$-value ${ }^{\dagger}$} \\
\hline & Mean \pm SD & $\mathrm{n}$ & Mean \pm SD & $\mathrm{n}$ & Mean \pm SD & $\mathrm{n}$ & Mean \pm SD & $\mathrm{n}$ & \\
\hline \multicolumn{10}{|c|}{$\log _{10}$ SDNN (msec) } \\
\hline District A & $1.67 \pm 0.17$ & 125 & $1.71 \pm 0.16$ & 42 & $1.68 \pm 0.17$ & 42 & $1.62 \pm 0.16$ & 41 & $0.007^{* *}$ \\
\hline District B & $1.71 \pm 0.19$ & 108 & $1.69 \pm 0.18$ & 31 & $1.70 \pm 0.19$ & 40 & $1.72 \pm 0.20$ & 37 & 0.98 \\
\hline Total & $1.69 \pm 0.18$ & 233 & $1.70 \pm 0.17$ & 73 & $1.69 \pm 0.18$ & 82 & $1.67 \pm 0.18$ & 78 & 0.066 \\
\hline \multicolumn{10}{|c|}{$\log _{10} \mathrm{r}-\mathrm{MSSD}(\mathrm{msec})$} \\
\hline District A & $1.50 \pm 0.22$ & 125 & $1.53 \pm 0.21$ & 42 & $1.52 \pm 0.24$ & 42 & $1.44 \pm 0.21$ & 41 & 0.072 \\
\hline District B & $1.54 \pm 0.25$ & 108 & $1.51 \pm 0$ & 31 & $1.54 \pm 0$ & 40 & $1.57 \pm 0.27$ & 37 & 0.61 \\
\hline Total & $1.52 \pm 0.24$ & 233 & $1.52 \pm 0.23$ & 73 & $1.52 \pm 0.23$ & 82 & $1.51 \pm 0.25$ & 78 & 0.37 \\
\hline \multicolumn{10}{|c|}{$\begin{array}{l}\text { tp-value for trend across three different measurements; }{ }^{* * *} p<0.001{ }^{* *} p<0.01{ }^{*} p<0.05 \\
\text { SDNN = standard deviation of all normal to normal intervals; r-MSSD }=\text { the square root of the mean of the sum of the } \\
\text { squares of differences between adjacent NN intervals. }\end{array}$} \\
\hline \multicolumn{10}{|c|}{ Table 4. The GEE of HRV with regard to personal $\mathrm{PM}_{2.5}$ exposure and metals in $\mathrm{PM}_{2.5}$ in non-smoking participants } \\
\hline \multirow{2}{*}{ Predictors } & & & \multicolumn{3}{|c|}{$\log _{10}$ SDNN (msec) } & \multicolumn{3}{|c|}{$\log _{10} \mathrm{r}-\mathrm{MSSD}(\mathrm{msec})$} & \\
\hline & & & \multicolumn{3}{|c|}{ Regression coefficient $(95 \% \mathrm{CIs}){ }^{\dagger}$} & \multicolumn{4}{|c|}{ Regression coefficient $(95 \% \text { CIs })^{\dagger}$} \\
\hline \multicolumn{3}{|c|}{$\log _{10} \mathrm{PM}_{2.5}\left(\mu \mathrm{g} \mathrm{m}^{-3}\right)$} & \multicolumn{3}{|c|}{$-0.041(-0.14$ to 0.057$)$} & \multicolumn{4}{|c|}{$-0.091(-0.21$ to 0.026$)$} \\
\hline \multicolumn{3}{|c|}{$\log _{10}$ Iron in $\mathrm{PM}_{2.5}\left(\mathrm{ng} \mathrm{m}^{-3}\right)$} & \multicolumn{3}{|c|}{$-0.033(-0.060 \text { to }-0.0056)^{*}$} & \multicolumn{4}{|c|}{$-0.041(-0.075 \text { to }-0.0076)^{*}$} \\
\hline \multicolumn{3}{|c|}{$\log _{10}$ Titanium in $\mathrm{PM}_{2.5}\left(\mathrm{ng} \mathrm{m}^{-3}\right)$} & \multicolumn{3}{|c|}{$-0.0079(-0.052$ to 0.036$)$} & \multicolumn{4}{|c|}{$-0.040(-0.094$ to 0.013$)$} \\
\hline \multicolumn{3}{|c|}{$\log _{10}$ Nickel in $\mathrm{PM}_{2.5}\left(\mathrm{ng} \mathrm{m}^{-3}\right)$} & \multirow{2}{*}{\multicolumn{3}{|c|}{0.0032 (-0.036 to 0.043$)$}} & \multicolumn{4}{|c|}{$0.028(-0.020$ to 0.076$)$} \\
\hline \multicolumn{3}{|c|}{$\log _{10}$ Manganese in $\mathrm{PM}_{2.5}\left(\mathrm{ng} \mathrm{m}^{-3}\right)$} & \multirow{2}{*}{\multicolumn{3}{|c|}{$\begin{array}{l}-0.031(-0.069 \text { to } 0.0068) \\
0.054(0.0064 \text { to } 0.10)^{*}\end{array}$}} & \multirow{2}{*}{\multicolumn{4}{|c|}{$\begin{array}{l}-0.026(-0.073 \text { to } 0.020) \\
0.054(-0.0030 \text { to } 0.11)\end{array}$}} \\
\hline \multicolumn{3}{|c|}{$\log _{10}$ Gallium in $\mathrm{PM}_{2.5}\left(\mathrm{ng} \mathrm{m}^{-3}\right)$} & & & & & & & \\
\hline
\end{tabular}

Adjusted for the age, gender, sampling area, sampling times, day of the week, temperature, relative humidity, noise. $\dagger^{* * *} p<0.001^{* *} p<0.01{ }^{*} p<0.05$.

SDNN = standard deviation of all normal to normal intervals; $r-M S S D=$ the square root of the mean of the sum of the squares of differences between adjacent $\mathrm{NN}$ intervals; $95 \% \mathrm{CI}=95 \%$ Confidence Interval.

$(25-75$ percentile $=36.36-67.58(\mathrm{msec}))$ and the r-MSSD of the total study subjects' median was $34.42 \mathrm{msec}$ (25-75 percentile $=23.23-49.24(\mathrm{msec}))$. In the third measurement, the SDNN of the total study subjects' median was $43.69 \mathrm{msec}$ $(25-75$ percentile $=32.97-57.91(\mathrm{msec}))$ and the r-MSSD of the total study subjects' median was $28.09 \mathrm{msec}$ (25-75 percentile $=21.86-44.47(\mathrm{msec})$ ). In previous studies, SDNN levels below $50 \mathrm{msec}$ represented unhealthy and r-MSSD levels below $42 \mathrm{msec}$ represented higher CV risk. Previous studies that compared short-term to 24-hour measurements showed that the HRV index of short-term HRV measurements may be lower than that of 24-hour measurements (Lin et al., 2005; Shaffer and Ginsberg, 2017).

In the present study, a significant decrease in HRV was related to an increase in iron particulates. The SDNN levels of HRV were significantly positively related to gallium particulates. A change in HRV represents an ANS imbalance and could cause an increased risk of mortality (Electrophysiology, 1996). Higher SDNN levels represented a lower risk of mortality, whereas SDNN levels below $50 \mathrm{msec}$ represented an unhealthy status. Also, lower r-MSSD levels represented a higher risk of death (Shaffer and Ginsberg, 2017). In a randomized crossover study near steel plants, Shutt et al. (2017) found that the SDNN intervals of participants who were exposed to possible air pollution and metal elements significantly decreased. Chen et al. (2015) found that exposure to metal particulates may cause adverse autonomic responses in high-cardiovascular risk workers. In a previous study, many elements were associated with changes in HRV. In a panel study, Wu et al. (2012) found that calcium in airborne particulate matter decreased the r-MSSD of HRV. Cavallari et al. (2008) found that manganese in $\mathrm{PM}_{2.5}$ was associated with night-time r-MSSDs of HRV in boilermakers. In an epidemiologic study, lead and vanadium concentrations in $\mathrm{PM}_{2.5}$ were associated with changes in HRV in boilermakers (Magari et al., 2002). A Taiwanese study found that metal elements such as nickel may regulate HRV by increasing oxidative stress and causing inflammatory responses (Chuang et al., 2013). Gallium is present in only trace amounts in the natural environment. Currently, potential exposure to gallium is receiving attention due to expanding electronics and energy technologies (White and Shine, 2016). There is no established evidence to explain its effects on the human body; thus, it may need further investigation.

There were limitations in this study. First, we used sampling noise for adjustment rather than personal noise dosimeter data. In addition, the measurements were repeated in February, April and June over a six-month study period. As such, lagged effects could not be explored. Third, in our study, we did not collect data on personal exposure to other air pollutants and $\mathrm{PM}_{2.5}$ components. Thus, various factors may still confound the associations between heavy metals in $\mathrm{PM}_{2.5}$ and ANS dysfunction. Fourth, we used 24-hour mean $\mathrm{PM}_{2.5}$ levels, metals in $\mathrm{PM}_{2.5}$ concentrations and 5-minute mean SDNN and r-MSSD levels to investigate the associations between heavy metals in $\mathrm{PM}_{2.5}$ and ANS dysfunction. 
Although the SDNN represented the overall HRV index clinically, the associations between heavy metals in $\mathrm{PM}_{2.5}$ and ANS dysfunction cannot be explored throughout due to a lack of information on the 24-hour mean SDNN and r-MSSD. Finally, we did not differentiate indoor airborne particulate matter from outdoor airborne particulate matter.

\section{CONCLUSIONS}

In summary, elevated levels of iron in $\mathrm{PM}_{2.5}$ are associated with decreases in both the SDNN intervals and the r-MSSDs between adjacent NN intervals of HRV. In addition, the levels of gallium in $\mathrm{PM}_{2.5}$ were positively associated with the SDNN of HRV. The health effects of metal particulates should not be underestimated.

\section{FUNDING}

This study was supported by grants (NSC102-EPA-F003-001 and 103-2314-B-016-007) from the Environmental Protection Administration and National Science Council of Taiwan, Republic of China and the Ministry of Science and Technology.

\section{CONFLICT OF INTEREST}

The author(s) declare no competing interests.

\section{ACKNOWLEDGEMENTS}

The authors wish to thank Dr. Saou-Hsing Liou for the developing research project of this study.

\section{REFERENCES}

Adar, S.D., Gold, D.R., Coull, B.A., Schwartz, J., Stone, P.H. and Suh, H. (2007). Focused exposures to airborne traffic particles and heart rate variability in the elderly. Epidemiology 18: 95-103. https://doi.org/10.1097/01.ed e.0000249409.81050.46

Block, M.L. and Calderon-Garciduenas, L. (2009). Air pollution: Mechanisms of neuroinflammation and cns disease. Trends Neurosci. 32: 506-516. https://doi.org/10. 1016/j.tins.2009.05.009

Brook, R.D., Rajagopalan, S., Pope, C.A., 3rd, Brook, J.R., Bhatnagar, A., Diez-Roux, A.V., Holguin, F., Hong, Y., Luepker, R.V., Mittleman, M.A., Peters, A., Siscovick, D., Smith, S.C., Jr., Whitsel, L. and Kaufman, J.D. (2010). Particulate matter air pollution and cardiovascular disease: An update to the scientific statement from the american heart association. Circulation 121: 2331-2378. https://doi.org/10.1161/CIR.0b013e3181dbece1

Cavallari, J.M., Eisen, E.A., Fang, S.C., Schwartz, J., Hauser, R., Herrick, R.F. and Christiani, D.C. (2008). $\mathrm{PM}_{2.5}$ metal exposures and nocturnal heart rate variability: A panel study of boilermaker construction workers. Environ. Health 7: 36. https://doi.org/10.1186/1 476-069x-7-36

Chang, C.C., Yuan, C.S., Li, T.C., Su, Y.L., Tong, C. and
Wu, S.P. (2018). Chemical characteristics, source apportionment, and regional transport of marine fine particles toward offshore islands near the coastline of northwestern Taiwan Strait. Environ. Sci. Pollut. Res. Int. 25: 32332-32345. https://doi.org/10.1007/s11356-0183093-9

Chen, J.C., Stone, P.H., Verrier, R.L., Nearing, B.D., MacCallum, G., Kim, J.Y., Herrick, R.F., You, J., Zhou, H. and Christiani, D.C. (2006). Personal coronary risk profiles modify autonomic nervous system responses to air pollution. J. Occup. Environ. Med. 48: 1133-1142. https://doi.org/10.1097/01.jom.0000245675.85924.7e

Chen, Y.C., Hsu, C.Y., Lin, S.L., Chang-Chien, G.P., Chen, M.J., Fang, G.C. and Chiang, H.C. (2015). Characteristics of concentrations and metal compositions for $\mathrm{PM}_{2.5}$ and $\mathrm{PM}_{2.5-10}$ in yunlin county, taiwan during air quality deterioration. Aerosol Air Qual. Res. 15: 2571-2583. https://doi.org/10.4209/aaqr.2015.04.0261

Chuang, H.C., Hsueh, T.W., Chang, C.C., Hwang, J.S., Chuang, K.J., Yan, Y.H. and Cheng, T.J. (2013). Nickelregulated heart rate variability: The roles of oxidative stress and inflammation. Toxicol. Appl. Pharmacol. 266: 298-306. https://doi.org/10.1016/j.taap.2012.11.006

Cowell, W.J., Brunst, K.J., Malin, A.J., Coull, B.A., Gennings, C., Kloog, I., Lipton, L., Wright, R.O., Enlow, M.B. and Wright, R.J. (2019). Prenatal exposure to $\mathrm{PM}_{2.5}$ and cardiac vagal tone during infancy: Findings from a multiethnic birth cohort. Environ. Health Perspect. 127: 107007. https://doi.org/10.1289/EHP4434

Electrophysiology - Task Force of the European Society of Cardiology and the North American Society of Pacing and Electrophysiology (1996). Heart rate variability. Circulation 93: 1043-1065. https://doi.org/10.1161/01.C IR.93.5.1043

Fang, G.C., Chang, C.N., Chu, C.C., Wu, Y.S., Fu, P.P., Yang, I.L. and Chen, M.H. (2003). Characterization of particulate, metallic elements of TSP, $\operatorname{PM}(2.5)$ and $\operatorname{PM}(2.5-10)$ aerosols at a farm sampling site in Taiwan, Taichung. Sci. Total Environ. 308: 157-166. https://doi.org/10.1016/s00489697(02)00648-4

Fang, S.C., Wu, Y.L. and Tsai, P.S. (2019). Heart rate variability and risk of all-cause death and cardiovascular events in patients with cardiovascular disease: A metaanalysis of cohort studies. Biol. Res. Nurs. 22: 45-56. https://doi.org/10.1177/1099800419877442

Fiordelisi, A., Piscitelli, P., Trimarco, B., Coscioni, E., Iaccarino, G. and Sorriento, D. (2017). The mechanisms of air pollution and particulate matter in cardiovascular diseases. Heart Fail. Rev. 22: 337-347. https://doi.org/10. 1007/s10741-017-9606-7

Geiger, A. and Cooper, J. (2010) Overview of airborne metals regulations, exposure limits, health effects, and contemporary research. Environmental Protection Agency, Portland, pp. 1-56. https://www3.epa.gov/ttnem c01/prelim/otm31 appC.pdf

Jia, X., Yang, X., Hu, D., Dong, W., Yang, F., Liu, Q., Li, H., Pan, L., Shan, J., Niu, W., Wu, S., Deng, F. and Guo, X. (2018). Short-term effects of particulate matter in metro cabin on heart rate variability in young healthy adults: 
Impacts of particle size and source. Environ. Res. 167: 292-298. https://doi.org/10.1016/j.envres.2018.07.017

Kim, S.Y., Kim, J.K., Park, S.H., Kim, B.G., Jang, A.S., Oh, S.H., Lee, J.H., Suh, M.W. and Park, M.K. (2018). Effects of inhaled particulate matter on the central nervous system in mice. Neurotoxicology 67: 169-177. https://doi.org/10.1016/j.neuro.2018.06.001

Krishnan, R.M., Sullivan, J.H., Carlsten, C., Wilkerson, H.W., Beyer, R.P., Bammler, T., Farin, F., Peretz, A. and Kaufman, J.D. (2013). A randomized cross-over study of inhalation of diesel exhaust, hematological indices, and endothelial markers in humans. Part. Fibre Toxicol. 10: 7. https://doi.org/10.1186/1743-8977-10-7

Li, T.C., Yuan, C.S., Huang, H.C., Lee, C.L., Wu, S.P. and Tong, C. (2016). Inter-comparison of seasonal variation, chemical characteristics, and source identification of atmospheric fine particles on both sides of the Taiwan Strait. Sci. Rep. 6: 22956. https://doi.org/10.1038/srep22 956

Lin, K.P., Lin, G.H. and Chang, Y.H. (2005). Comparison of heart rate variability measured by ECG in different signal lengths. J. Med. Biol. Eng. 25: 67-71. http://www.jmbe. org.tw/index.php?action=archives $2 \& n o=161$

Madsen, C., Rosland, P., Hoff, D.A., Nystad, W., Nafstad, P. and Naess, O.E. (2012). The short-term effect of 24-h average and peak air pollution on mortality in Oslo, Norway. Eur. J. Epidemiol. 27: 717-727. https://doi.org/ 10.1007/s10654-012-9719-1

Magari, S.R., Schwartz, J., Williams, P.L., Hauser, R., Smith, T.J. and Christiani, D.C. (2002). The association of particulate air metal concentrations with heart rate variability. Environ. Health Perspect. 110: 875-880. https://doi.org/10.1289/ehp.02110875

Mirowsky, J.E., Peltier, R.E., Lippmann, M., Thurston, G., Chen, L.C., Neas, L., Diaz-Sanchez, D., Laumbach, R., Carter, J.D. and Gordon, T. (2015). Repeated measures of inflammation, blood pressure, and heart rate variability associated with traffic exposures in healthy adults. Environ. Health 14: 66. https://doi.org/10.1186/s12940015-0049-0

Moritani, T., Kimura, T., Hamada, T. and Nagai, N. (2005). Electrophysiology and kinesiology for health and disease. J. Electromyogr. Kinesiol. 15: 240-255. https://doi.org/ 10.1016/j.jelekin.2005.01.001

Riediker, M., Cascio, W.E., Griggs, T.R., Herbst, M.C., Bromberg, P.A., Neas, L., Williams, R.W. and Devlin, R.B. (2004). Particulate matter exposure in cars is associated with cardiovascular effects in healthy young men. Am. J. Respir. Crit. Care Med. 169: 934-940. https://doi.org/10.1164/rccm.200310-1463OC
Schwela, D. (2000). Air pollution and health in urban areas. Rev. Environ. Health 15: 13-42. https://doi.org/10.1515/ reveh.2000.15.1-2.13

Shaffer, F. and Ginsberg, J.P. (2017). An overview of heart rate variability metrics and norms. Front. Public Health 5: 258-258. https://doi.org/10.3389/fpubh.2017.00258

Shutt, R.H., Kauri, L.M., Weichenthal, S., Kumarathasan, P., Vincent, R., Thomson, E.M., Liu, L., Mahmud, M., Cakmak, S. and Dales, R. (2017). Exposure to air pollution near a steel plant is associated with reduced heart rate variability: A randomised crossover study. Environ. Health 16: 4. https://doi.org/10.1186/s12940016-0206-0

Wang, C.F., Jeng, S.L. and Shieh, F.J. (1997). Determination of arsenic in airborne particulate matter by inductively coupled plasma mass spectrometry J. Anal. At. Spectrom. 12: 61-67. https://doi.org/10.1039/A6056 $58 \mathrm{~J}$

Wang, Y., Xiong, L. and Tang, M. (2017). Toxicity of inhaled particulate matter on the central nervous system: Neuroinflammation, neuropsychological effects and neurodegenerative disease. J. Appl. Toxicol. 37: 644-667. https://doi.org/10.1002/jat.3451

White, S.J.O. and Shine, J.P. (2016). Exposure potential and health impacts of indium and gallium, metals critical to emerging electronics and energy technologies. Curr. Environ. Health Rep. 3: 459-467. https://doi.org/10.100 7/s40572-016-0118-8

Wu, Li, Y.R., Kuo, I.C., Hsu, S.C., Lin, L.Y. and Su, T.C. (2012). Investigating the association of cardiovascular effects with personal exposure to particle components and sources. Sci. Total Environ. 431: 176-182. https://doi.org/10.1016/j.scitotenv.2012.05.015

Wu, S., Deng, F., Niu, J., Huang, Q., Liu, Y. and Guo, X. (2010). Association of heart rate variability in taxi drivers with marked changes in particulate air pollution in Beijing in 2008. Environ. Health Perspect. 118: 87-91. https://doi.org/10.1289/ehp.0900818

Zeger, S.L. and Liang, K.Y. (1986). Longitudinal data analysis for discrete and continuous outcomes. Biometrics 42: 121-130.

Zhang, J.J. and Samet, J.M. (2015). Chinese haze versus western smog: Lessons learned. J. Thorac. Dis. 7: 3-13. https://doi.org/10.3978/j.issn.2072-1439.2014.12.06

Received for review, April 19, 2020 Revised, June 20, 2020 Accepted, July 2, 2020 